\title{
Treatment and outcome of 32 patients with distant metastases of Hürthle cell thyroid carcinoma: a single-institution experience
}

\author{
Nikola Besic ${ }^{{ }^{*}}$ (D) Andreja Schwarzbartl-Pevec ${ }^{2}$, Barbara Vidergar-Kralj², Tea Crnic $^{2}$, Barbara Gazic ${ }^{3}$ \\ and Maja Marolt Music ${ }^{4}$
}

\begin{abstract}
Background: It is generally believed that patients with Hürthle cell thyroid carcinoma (HCTC) have a poor prognosis. Furthermore, distant metastases represent the most frequent cause of thyroid cancer-related death of patients with HCTC. The aim of this study was to report the treatment and outcomes of patients with distant metastases.

Methods: Altogether 108 patients were treated for HCTC from 1972 to 2011 in our tertiary center and 32 patients (19 females, 13 males; median age 64.5 years) had either initially proven metastatic disease $(N=12)$ or distant progression of HCTC after initial treatment $(N=20)$. Patients with metastases were followed for 1-226 (median 77) months. Data were collected on the patients' gender and age, extent of their disease, morphologic characteristics, therapy, outcome, and survival rate. Statistical correlation between possible prognostic factors and cause-specific survival from time of detection of metastases was analyzed by univariate analysis and log-rank test.
\end{abstract}

Results: The most common were lung metastases, followed by bone, mediastinum, kidney, and liver in 24, 8, 2, 1, and 1 case, respectively. Total thyroidectomy, lobectomy, subtotal thyroidectomy and neck dissection were performed in $19,10,3$ and 7 patients, respectively. Radioiodine (RAI) ablation of thyroid remnant was performed in 30 patients, while 20 of them had RAl therapy (median 4 times). RAl uptake in metastases was present in 16 patients and ranged from $0.05 \%$ to $12 \%$. Chemotherapy was used in 13 patients and external beam radiotherapy in 19 patients. Locoregional control of disease was achieved in 19/21 (90 \%) cases who succumbed due to HCTC. Estimated 10-year disease-specific survival for all patients was $60 \%$. 10-year disease-specific survival for patients with pulmonary metastases and other sites metastases was $60 \%$ and $62 \%$, respectively. 10-year disease-specific survival for patients with single organ and multiple organ metastases was $52 \%$, and $100 \%$, respectively. Estimated median disease-specific survival after the diagnosis of metastatic disease for all patients was 77 months. The median disease-specific survival after the diagnosis of metastatic disease for patients with pulmonary metastases and other sites metastases was 72 and 138 months, respectively.

Conclusions: Ten-year disease-specific survival for all patients with metastatic Hürthle cell thyroid carcinoma, patients with pulmonary metastases and bone metastases was $60 \%, 60 \%$ and $68 \%$, respectively.

Keywords: Thyroid carcinoma, Treatment, Radioiodine, Hürthle cell thyroid carcinoma, Surgery, Radiotherapy, Outcome, Pathology

\footnotetext{
* Correspondence: nbesic@onko-i.si

'Department of Surgical Oncology, Institute of Oncology, Zaloska 2, SI-1000

Ljubljana, Slovenia

Full list of author information is available at the end of the article
} 


\section{Background}

Hürthle cell thyroid carcinoma (HCTC) is regarded to be an oxyphilic variant of follicular thyroid cancer (FTC) according to the World Health Organization classification [1]. However, genomic studies revealed that HCTC is a unique thyroid malignancy distinct from papillary and follicular thyroid cancer [2]. HCTC is a rare type of thyroid carcinoma [3] which comprises about $3 \%$ of all thyroid malignancies [4].

Only about 400 patients with HCTC were reported from 1935 to 2004 [3]. There are several reports of single-institution studies of patients with HCTC [5-23], but only two recently published single-institution series included more than 100 patients $[22,23]$. Older studies reported poor survival of patients with $\mathrm{HCTC}[5,6,8-10]$. But in population-based studies from the United States, Nagar et al. [24] and Bhattacharyya [2] reported that the survival of patients with HCTC has improved dramatically over time and that survival rates of HCTC and FTC are currently the same. Unfortunately, the treatment of patients was not reported and causes of prolonged survival were not explained.

In 2003, we reported that the uptake of radioiodine (RAI) was confirmed in 11 of 16 patients with metastatic HCTC [15]. The purpose of the present study was to report the uptake of RAI in a larger number of patients with metastatic HCTC. Another of this study's aims was to describe the treatment and outcome of 32 patients with metastatic HCTC with a long follow-up period.

\section{Methods}

Altogether 108 patients were treated for HCTC at our tertiary center from 1972 to 2011, and 32 patients (19 females, 13 males; median age 64.5 years) had either an initially proven metastatic disease $(N=12 ; 9$ females, 3 males; median age 66.5 years) or distant progression of HCTC after initial treatment $(N=20 ; 10$ females, 10 males; median age 64 years).

The Medical Ethics Committee of the Republic Slovenia and The Protocol Review Board and Ethics Committee of the Institute of Oncology approved the study, which was conducted in accordance with the ethical standards laid down in an appropriate version of the 1964 Declaration of Helsinki. The need for consent was waived by the Institutional Review Board and Ethics Committee of the Institute of Oncology Ljubljana. For retrospective studies a written consent is deemed unnecessary according to national regulations.

As already reported in one of our previous studies [23], all histological slides of our patients with HCTC were examined by the pathologist (B.G.) experienced in thyroid pathomorphology. HCTC was diagnosed on the histological criteria defined by LiVolsi and Rosai $[25,26]$. An oncocyte was characterized by the presence of acidophilic, granular cytoplasm and hyperchromatic or vesicular nuclei with large nucleolus. Only lesions demonstrating more than $75 \%$ of follicular cells with oncocytic characteristics were included in the study group. All patients with Hürthle cell neoplasms with cells containing typical nuclear features of papillary carcinoma were excluded from our present study and were the subject of one of our previous studies [27]. The diagnosis of malignancy for present study was based on histologic evidence of transcapsular and/or vascular invasion, extrathyroidal local tissue invasion by the primary tumor $[25,26]$, or presence of nodal or distant metastasis.

A chart review was performed, and data on patients' age, gender, disease history, extent of disease, histomorphological characteristics, mode of therapy, outcome, and survival were collected. Clinical characteristics, treatment of patients and their outcome are presented in Table 1, Table 2 and Table 3.

The tumor stage, presence of regional and/or distant metastases, as well as residual tumor after surgery were assessed by the TNM clinical classification according to the UICC criteria from 2009 [28]. The initial diagnostic work-up in all patients with HCTC included ultrasound (US) of the neck region, determination of the serum thyroglobulin ( Tg) concentration and chest X-ray. The criteria for disease-free survival were Tg levels of less than $1 \mathrm{ng} / \mathrm{mL}$, negative whole-body RAI scans, and the exclusion of cervical lymph node metastases by US. Additional diagnostic work-up (X-ray, US, computed tomography, magnetic resonance imaging, bone scintigraphy, scintigraphy with MIBI and/or PET-CT) was conducted whenever the medical history, physical examination, laboratory findings, and/or radioiodine (RAI) uptake indicated recurrence and/or distant metastases.

All patients with HCTC had a follow-up exam at our Institute at least once per year, while for all patients with distant metastases follow-ups were conducted at least twice per year. This consisted of obtaining medical history, a physical examination, and determining serum Tg concentration. Imaging was also conducted whenever $\mathrm{Tg}$ concentration increased or clinical symptoms suggested that the disease had progressed.

\section{Treatment}

During 30 year period, surgical treatment of primary tumor, locoregional recurrences, and distant metastases was not uniform; neither was the proportion of patients treated by RAI ablation of thyroid remnant tissue, external beam radiotherapy (EBRT), chemotherapy and RAI therapy [23]. Surgery is the mainstay of the treatment of HCTC. Among surgically treated patients, $84 \%$ had primary surgery at the Institute of Oncology and $16 \%$ elsewhere, while all other specific therapies (surgery, RAI, EBRT and/or chemotherapy) as well as follow-up were 
Table 1 Patients' and tumor characteristics and univariate statistical analysis of disease-specific survival

\begin{tabular}{|c|c|c|c|c|}
\hline Factor & Subgroup & Initially metastatic $(N=12)$ & Distant progression $(N=20)$ & $p$-value \\
\hline \multirow[t]{2}{*}{ Gender } & Female & 9 & 10 & 0.16 \\
\hline & Male & 3 & 10 & \\
\hline \multirow[t]{2}{*}{ Age at presentation (years) } & 64 or less & 6 & 5 & 0.15 \\
\hline & 65 or more & 6 & 15 & \\
\hline \multirow[t]{2}{*}{ Tumor diameter $(\mathrm{cm})$} & $0-4$ & 3 & 4 & 0.74 \\
\hline & 4.01 and more & 9 & 16 & \\
\hline \multirow[t]{3}{*}{ pT tumor stage } & pT0 or pT2 & 2 & 3 & 0.96 \\
\hline & pT3 & 6 & 11 & \\
\hline & pT4 & 4 & 6 & \\
\hline \multirow[t]{2}{*}{ N stage } & No & 10 & 16 & 0.48 \\
\hline & $\mathrm{N} 1(\mathrm{~N} 1 \mathrm{a}+\mathrm{N} 1 \mathrm{~b})$ & 2 & 4 & \\
\hline \multirow[t]{2}{*}{ M stage } & MO & 12 & 0 & - \\
\hline & M1 & 0 & 20 & \\
\hline \multirow[t]{2}{*}{ Thyroid surgical procedure } & Total or near-total thyroidectomy & 6 & 13 & 0.40 \\
\hline & Lobectomy or less & 6 & 7 & \\
\hline \multirow[t]{2}{*}{ Neck dissection } & No & 9 & 18 & 0.26 \\
\hline & Yes & 3 & 2 & \\
\hline \multirow[t]{3}{*}{ Residual tumor after surgery } & RO - without residual tumor & 3 & 12 & 0.066 \\
\hline & R1 - microscopic residual tumor & 8 & 5 & \\
\hline & R2- macroscopic residual tumor & 1 & 3 & \\
\hline \multirow[t]{2}{*}{ Radioiodine ablation after surgery } & No & 1 & 1 & 0.71 \\
\hline & Yes & 11 & 19 & \\
\hline \multirow[t]{2}{*}{ Therapy with radioiodine } & No & 5 & 8 & 0.93 \\
\hline & Yes & 7 & 12 & \\
\hline \multirow[t]{2}{*}{ External beam irradiation - neck } & No & 6 & 14 & 0.40 \\
\hline & Yes & 6 & 6 & \\
\hline \multirow[t]{2}{*}{ External beam irradiation - any site } & No & 2 & 11 & 0.03 \\
\hline & Yes & 10 & 9 & \\
\hline \multirow[t]{2}{*}{ Chemotherapy } & No & 4 & 16 & 0.008 \\
\hline & Yes & 8 & 4 & \\
\hline \multirow[t]{5}{*}{ Outcome } & Alive without disease & 0 & 0 & - \\
\hline & Alive with disease & 2 & 9 & \\
\hline & Dead of disease & 9 & 11 & \\
\hline & Dead of other causes & 0 & 0 & \\
\hline & Lost to follow-up & 1 & 0 & \\
\hline
\end{tabular}

conducted for all patients at the Institute of Oncology. After surgery, all patients received therapy with Lthyroxin for thyrotropin (TSH) suppression.

The data on the type of surgery for primary tumors and treatment of distant metastasis are listed in Table 3. Total or near-total thyroidectomy is considered a proper surgical procedure for HCTC. Generally, after an inadequate surgical procedure a completion thyroidectomy is performed. However, in our study group this was performed in only one of 13 patients with inadequate surgery. It was not performed if the patient had an injury of recurrent nerve $(N=2)$, or if the patient was very old or with severe comorbidities $(N=2)$, if the patient refused another surgical procedure $(N=2)$, and preferred treatment with RAI $(N=6)$.

Initial treatment in nine patients with a locally advanced tumor was neoadjuvant chemotherapy, while one patient received concomitant EBRT with a tumor dose of 36 Gy. Tumor size decreased in all of these patients, and in 2 of 9 patients the largest tumor diameter 
Table 2 Clinical characteristics of 32 patients and their outcome

\begin{tabular}{|c|c|c|c|c|c|c|c|c|c|c|c|c|}
\hline $\begin{array}{l}\text { Patient } \\
\text { number }\end{array}$ & $\begin{array}{l}\text { Age range } \\
\text { at presentation }\end{array}$ & $\begin{array}{l}\text { Age range } \\
\text { at metastases }\end{array}$ & $\begin{array}{l}\text { Tumor } \\
\text { diameter } \\
(\mathrm{cm})\end{array}$ & $\begin{array}{l}\text { pT- } \\
\text { stage }\end{array}$ & $\begin{array}{l}\mathrm{pN}- \\
\text { stage }\end{array}$ & $\begin{array}{l}\mathrm{M}- \\
\text { stage }\end{array}$ & $\begin{array}{l}\text { Site of } \\
\text { metastases }\end{array}$ & $\begin{array}{l}\text { Tg at diagnosis } \\
\text { of metastases }\end{array}$ & Survival & $\begin{array}{l}\text { Disease-free } \\
\text { interval }\end{array}$ & $\begin{array}{l}\text { Survival from } \\
\text { diagnosis of } \\
\text { distant } \\
\text { metastases }\end{array}$ & $\begin{array}{l}\text { Cause of } \\
\text { death }\end{array}$ \\
\hline 1 & $85-89$ & $85-89$ & 7,5 & 3 & 0 & 1 & $L$ & 7414 & 77 & 0 & 77 & DDM \\
\hline 2 & $75-79$ & $75-79$ & 5 & $4 b$ & 0 & 1 & L & 4450 & 53 & 0 & 53 & DOC \\
\hline 3 & $70-74$ & $70-74$ & 8 & 3 & 0 & 1 & L & 265 & 141 & 0 & 141 & DDM \\
\hline 4 & $70-74$ & $70-74$ & 6 & $4 a$ & 0 & 1 & B & 183 & 13 & 0 & 13 & DDM \\
\hline 5 & $65-69$ & $65-69$ & 8,5 & 3 & 0 & 1 & L & 16650 & 185 & 0 & 185 & Alive \\
\hline 6 & $65-69$ & $65-69$ & 8 & 3 & 0 & 1 & $B L$ & 4010 & 148 & 0 & 148 & DDM \\
\hline 7 & $60-64$ & $60-64$ & 8 & 0 & 0 & 1 & B & No data & 153 & 0 & 153 & DDM \\
\hline 8 & $60-64$ & $60-64$ & 4,5 & 3 & $1 b$ & 1 & L & 62600 & 131 & 0 & 131 & DDM \\
\hline 9 & $60-64$ & $60-64$ & 2 & 2 & 0 & 1 & B & 69 & 1 & 0 & 1 & LFU \\
\hline 10 & $60-64$ & $60-64$ & 6,5 & 3 & 0 & 1 & L & 1300 & 72 & 0 & 72 & DDM \\
\hline 11 & $55-59$ & $55-59$ & 5 & $4 b$ & $1 b$ & 1 & L & 190 & 201 & 0 & 201 & DDM \\
\hline 12 & $45-49$ & $45-49$ & 9 & $4 b$ & 0 & 1 & L & 5800 & 52 & 0 & 52 & DDM \\
\hline 13 & $85-89$ & $85-89$ & 12 & 3 & 0 & 0 & Mediastinum & 277 & 52 & 38 & 14 & DDM \\
\hline 14 & $75-79$ & $75-79$ & 3 & 2 & 0 & 0 & B & 47 & 126 & 34 & 92 & Alive \\
\hline 15 & $75-79$ & $85-89$ & 8 & 3 & 0 & 0 & L & 696 & 144 & 84 & 60 & DDM \\
\hline 16 & $70-74$ & $70-74$ & 2 & $4 a$ & $1 a$ & 0 & Kidney & 1432 & 318 & 180 & 138 & DDM \\
\hline 17 & $70-74$ & $75-79$ & 8 & 3 & 0 & 0 & L & 1300 & 63 & 36 & 2 & DDLTP \\
\hline 18 & $70-74$ & $80-84$ & 6,8 & 3 & 0 & 0 & L & 1000 & 132 & 96 & 36 & Alive \\
\hline 19 & $70-74$ & $70-74$ & 5,5 & $4 a$ & 0 & 0 & L & No data & 26 & 3 & 23 & DDM \\
\hline 20 & $65-69$ & $65-69$ & 3,6 & 3 & 0 & 0 & L & 0.1 & 46 & 43 & 3 & Alive \\
\hline 21 & $65-69$ & $70-74$ & 7 & $4 a$ & 0 & 0 & L & No data & 63 & 53 & 10 & DDM \\
\hline 22 & $65-69$ & $65-69$ & 9 & 3 & 0 & 0 & $B L$ & 1100 & 145 & 52 & 93 & DDM \\
\hline 23 & $60-64$ & $65-69$ & 18 & $4 b$ & $1 b$ & 0 & L & 416 & 100 & 20 & 53 & DDM \\
\hline 24 & $60-64$ & $70-74$ & 3 & 2 & 0 & 0 & $L$, liver & 501 & 121 & 84 & 36 & DDM \\
\hline 25 & $60-64$ & $65-69$ & 4,5 & 3 & 0 & 0 & L & 30773 & 97 & 49 & 48 & Alive \\
\hline 26 & $60-64$ & $70-74$ & 7 & 3 & 0 & 0 & L & 196 & 138 & 113 & 27 & Alive \\
\hline 27 & $60-64$ & $60-64$ & 6,5 & 3 & $1 a$ & 0 & B & 763 & 43 & 16 & 27 & Alive \\
\hline 28 & $60-64$ & $60-64$ & 8 & $4 a$ & 0 & 0 & Mediastinum & 1800 & 145 & 44 & 101 & DDLTP \\
\hline 29 & $50-54$ & $55-59$ & 13 & $4 b$ & 0 & 0 & L & 800 & 75 & 26 & 42 & DDM \\
\hline 30 & $50-54$ & $75-79$ & 6 & 3 & 0 & 0 & L & 163 & 337 & 31 & 65 & DDM \\
\hline 31 & $50-54$ & $50-54$ & 3 & 2 & $1 b$ & 0 & L & Tg-antibodies & 33 & 9 & 24 & Alive \\
\hline 32 & $35-39$ & $40-44$ & 4 & 3 & 0 & 0 & $B L$ & 108 & 286 & 60 & 226 & Alive \\
\hline
\end{tabular}

Legend: $B$ bone, $L$ lungs, DDM dead of distant metastases, DOC dead of other causes, LFU lost to follow-up, DDLTP dead of distant and locoregional tumor progression

decreased by more than $30 \%$. Neoadjuvant chemotherapy consisted of long infusion of low dose vinblastine ( $2 \mathrm{mg}$ in $12-\mathrm{h})$ in four patients and of vinblastine and doxorubicin ( $20 \mathrm{mg}$ in 2 -h infusion) in two patients. Neoadjuvant chemotherapy consisted of vinblastine, doxorubicin and mitoxantrone in one patient, while in two patients more than three cytostatic drugs were used (vinblastine, doxorubicin, docetaxel and cisplatin in one patient; vinblastine, cisplatin, doxorubicin, bleomycin, cyclophosphamide, mitoxantrone in another one).
Metastases in regional lymph nodes were treated surgically by functional radical neck dissection in five as part of primary treatment. Surgical therapy of metastatic disease and/or locoregional recurrence was conducted on nine patients (Table 3). It included neck dissection, resection of lung metastasis, resection of bone metastasis, resection of brain metastasis, resection of liver metastasis, nephrectomy, laminectomy, hip replacement, superficial parotidectomy, tracheal shaving, and tracheostomy. 
Table 3 Treatment of patients

\begin{tabular}{|c|c|c|c|c|c|c|c|c|c|c|c|c|}
\hline $\begin{array}{l}\text { Patient } \\
\text { number }\end{array}$ & $\begin{array}{l}\text { Initial } \\
\text { surgery }\end{array}$ & $\begin{array}{l}\text { Residual } \\
\text { tumor after } \\
\text { surgery }\end{array}$ & $\begin{array}{l}\text { RAl ablation } \\
\text { of thyroid } \\
\text { remnant }\end{array}$ & RAl uptake & $\begin{array}{l}\text { RAl applications: } \\
\text { ablation and } \\
\text { therapy (Number) }\end{array}$ & $\begin{array}{l}\text { RAl cumulative } \\
\text { dose (mCi) }\end{array}$ & $\begin{array}{l}\text { Neoadjuvant } \\
\text { ChT }\end{array}$ & ChT & $\begin{array}{l}\text { Preoperative } \\
\text { EBRT (Dose } \\
\text { in Gy) }\end{array}$ & $\begin{array}{l}\text { EBRT - neck and } \\
\text { mediastinum } \\
\text { (Dose in Gy) }\end{array}$ & EBRT of metastases & $\begin{array}{l}\text { Surgery for metastases } \\
\text { or recurrence }\end{array}$ \\
\hline 1 & $\pi$ & RO & No & - & 0 & - & No & No & No & No & No & No \\
\hline 2 & LO & $\mathrm{R} 1$ & Yes & No & 1 & 129 & No & No & No & Yes (50) & No & No \\
\hline 3 & LO & R1 & Yes & Yes & 7 & 1066 & No & No & No & Yes (50) & No & No \\
\hline 4 & LO & R2 & Yes & No & 1 & 94 & Yes & Yes & Yes (36) & Yes $(36+15)$ & Ribs, thorax & No \\
\hline 5 & $\pi$ & R1 & Yes & Yes & 4 & 500 & Yes & Yes & No & Yes (56) & $\begin{array}{l}\text { Lumbal vertebra, left } \\
\text { hip and left pelvis }\end{array}$ & No \\
\hline 6 & LO & $\mathrm{R} 1$ & Yes & Yes & 8 & 1201 & Yes & Yes & No & No & $\begin{array}{l}\text { Thoracic vertebra - } \\
\text { rwice }\end{array}$ & No \\
\hline 7 & PT & RO & Yes & No & 2 & 250 & No & Yes & No & No & $\begin{array}{l}\text { Frontal part of skull, } \\
\text { left orbita }\end{array}$ & Resection of right clavicle \\
\hline 8 & $\pi+R N D$ & $\mathrm{R} 1$ & Yes & No & 1 & 100 & Yes & Yes & No & No & Lungs twice & No \\
\hline 9 & $\pi$ & RO & Yes & No & 1 & 94 & No & No & No & No & No & No \\
\hline 10 & $\pi+R N D$ & R1 & Yes & Yes & 8 & 1355 & Yes & Yes & No & Yes (50) & No & No \\
\hline 11 & $L O+R N D$ & R1 & Yes & Yes & 8 & 1156 & Yes & Yes & No & Yes (45) & $\begin{array}{l}\text { Left hip twice, thorax, } \\
\text { right hip, brain, right } \\
\text { clavicle }\end{array}$ & No \\
\hline 12 & $\pi$ & R1 & Yes & Yes & 9 & 1278 & Yes & Yes & No & No & $\begin{array}{l}\text { Thoracic vertebra, } \\
\text { pelvis, cervical } \\
\text { vertebra }\end{array}$ & Laminectomy \\
\hline 13 & $\pi$ & $\mathrm{R} 1$ & No & - & 0 & - & No & No & No & No & No & No \\
\hline 14 & $\pi$ & RO & Yes & Yes & 5 & 779 & No & No & No & No & No & No \\
\hline 15 & $\pi$ & RO & Yes & No & 1 & 92 & No & No & No & No & No & Left hip replacemnt \\
\hline 16 & LO & RO & Yes & Yes & 6 & 1090 & No & No & No & No & No & Right nephrectomy \\
\hline 17 & $\pi$ & RO & Yes & No & 1 & 106 & No & No & No & No & No & No \\
\hline 18 & $\pi$ & RO & Yes & No & 1 & 261 & No & No & No & No & No & No \\
\hline 19 & LO & RO & Yes & Yes & 2 & 350 & No & No & No & No & No & No \\
\hline 20 & $\pi$ & R2 & Yes & No & 1 & 100 & No & No & No & Yes (50) & No & $\begin{array}{l}\text { Tracheal shaving of } \\
\text { recurrence }\end{array}$ \\
\hline 21 & PT & R2 & Yes & Yes & 2 & 230 & No & No & No & No & No & No \\
\hline 22 & $\pi$ & Ro & Yes & Yes & 2 & 300 & No & No & No & No & $\begin{array}{l}\text { Base of skull, lungs, } \\
\text { right neck }\end{array}$ & No \\
\hline 23 & $\pi+R N D$ & $\mathrm{R} 1$ & Yes & No & 1 & 100 & Yes & Yes & No & Yes (49) & Clavicle & No \\
\hline 24 & PT & $\mathrm{R} 1$ & Yes & Yes & 9 & 1296 & No & No & No & Yes (50) & No & No \\
\hline
\end{tabular}

No No

Yes (50)

No 
Table 3 Treatment of patients (Continued)

\begin{tabular}{|c|c|c|c|c|c|c|c|c|c|c|c|c|}
\hline 25 & $\pi$ & Ro & Yes & No & 2 & 244 & No & No & No & No & No & No \\
\hline 26 & $\pi$ & Ro & Yes & Yes & 3 & 382 & No & No & No & No & No & No \\
\hline 27 & $\pi+\mathrm{RND}$ & R1 & Yes & No & 1 & 95 & No & Yes & No & Yes (50) & $\begin{array}{l}\text { Sternum, clavicle, } \\
\text { right tibia }\end{array}$ & No \\
\hline 28 & LO & R1 & Yes & Yes & 11 & 1523 & No & Yes & No & Yes (50) & No & No \\
\hline 29 & LO & R2 & Yes & No & 2 & 263 & Yes & Yes & No & Yes (51) & Mediastinum, lungs & Tracheostomy, mRND \\
\hline 30 & LO & Ro & Yes & Yes & 2 & 230 & No & No & No & No & Mediastinum, lungs & $\begin{array}{l}\text { Resection of lung metastasis } \\
\text { and twice brain matastasis }\end{array}$ \\
\hline 31 & $\pi$ & Ro & Yes & Yes & 3 & 393 & No & No & No & No & No & Parotidectomy, mRND \\
\hline 32 & $\pi$ & Ro & Yes & No & 1 & 95 & No & Yes & No & No & $\begin{array}{l}\text { Pelvis, left elbow, } \\
\text { lumbar vertebra }\end{array}$ & $\begin{array}{l}6 \times \text { lung metastasis, } 5 \times \text { bone } \\
\text { metastasis, mediastinal lymph } \\
\text { nodes, liver metastasis, axillary } \\
\text { lymphadenectomy }\end{array}$ \\
\hline
\end{tabular}

Legend: $\pi$ total or near total thyroidectomy, LO lobectomy, PT partial thyroidectomy, RND modified radical neck dissection, RAl radioiodine, ChT chemotherapy, EBRT external beam radiotherapy 
RAI was used for the ablation of thyroid remnant tissue in 30 (94\%) patients. All 13 patients with nonadequate surgery had the ablation of thyroid remnant tissue. The ablation dose was 3.4-4.8 GBq $(92-129 \mathrm{mCi})$ of RAI. RAI was used also for treating of distant metastases and inoperable locoregional recurrences with empiric dose of 3.7-7.4 GBq (100-200 mCi). Patients with distant metastases underwent total thyroidectomy prior to treatment with RAI in order to increase the uptake of iodine in metastases and to speed up the treatment whenever possible. Before 2002, serum concentration of TSH of $>30 \mathrm{mU} / \mathrm{L}$ was achieved by a 4-6-week withdrawal of L-thyroxin suppression therapy. Since 2002, recombinant human TSH (rhTSH)-aided RAI therapy [29] has been used in altogether eight patients who were elderly with concomitant diseases, had a history of severe hypothyroid or compressive symptoms and/or evidence of tumor progression during thyroid hormone withdrawal.

Altogether 13 patients were treated with chemotherapy. Kinase inhibitors were not used in patients included in the present report.

EBRT was done in a total of 19 patients, of whom twelve received EBRT to the neck and superior mediastinum ( 3 after R2 resection and 9 after R1 resection).

\section{Survival}

Cause-specific survival was defined as the period from primary treatment (surgery, chemotherapy or EBRT) to death or the last follow-up.

Disease-free survival was defined as the period from primary treatment (surgery, chemotherapy or EBRT) to the radiologic or morphologic diagnosis of recurrence or the last follow-up. The median duration of follow-up was 8.3 years (range $0.1-28.1$ years).

\section{Statistical analysis}

The Student $t$-test or the Mann-Whitney $U$-test was used according to data distribution. The association between categorical variables was tested by the chi-square test or Fisher's exact test, as appropriate. All comparisons were two-sided and a $p$-value $<0.05$ was considered statistically significant. The statistical correlation between possible prognostic factors and cause-specific survival was analyzed by chi-square test and log rank analysis. The survival curves were calculated according to the Kaplan-Meier method. A multivariate statistical analysis was not performed because of the small number of patients. The statistical package PASW 18 (SPSS Inc., Chicago, IL, USA) was used for the analysis.

\section{Results}

The median age of patients with initially proven metastatic disease $(N=12)$ and distant progression of HCTC after initial treatment $(N=20)$ was 66.5 and 64 years, respectively. The median age of both groups of patients was not statistically different. A female-to-male ratio in initially proven metastatic disease and distant progression after initial treatment was 3:1 and 1:1, respectively. Gender distribution in both groups of patients was not statistically different $(p=0.27)$.

The tumor diameter ranged from 2 to $18 \mathrm{~cm}$ (median $6.65 \mathrm{~cm}$, mean $6.75 \mathrm{~cm}$ ). Median tumor size in initially metastatic disease and distant progression was $7 \mathrm{~cm}$ and $6.65 \mathrm{~cm}$, respectively $(p=0.75)$. Extrathyroid tumor growth was present in patients with and without initially proven metastatic disease and $75 \%$ and $40 \%$; respectively $(p=0.27)$.

Single organ and multiple organ metastases at the time of diagnosis of dissemination were diagnosed in 28 and 4 cases, respectively. The most common were lung metastases, followed by bone, mediastinum, kidney, and liver in $24,8,2,1$, and 1 case, respectively. Lung metastases were present in patients with initially proven metastatic disease and in patients with metastases after a disease-free interval in $75 \%(p=1.0)$. Bone metastases were present in patients with initially proven metastatic disease and in patients with metastases after a diseasefree interval in $33 \%$ and $20 \%$; respectively $(p=0.43)$.

Median $\mathrm{Tg}$ concentration at the diagnosis of metastases was $1050 \mathrm{ng} / \mathrm{mL}$ (range $47-62600 \mathrm{ng} / \mathrm{mL}$ ).

\section{Treatment}

The data on the type of treatment of patients are summarized in Table 1. All patients had surgical treatment on their primary tumor. Total (or-near total) thyroidectomy, lobectomy, subtotal thyroidectomy, and neck dissection were performed in 19, 10, 3, and 7 patients, respectively. RAI ablation of thyroid remnant was performed in 30 patients, while RAI therapy was performed in 20 of them. They received from 1 to 10 RAI therapies (median 4) and cumulative RAI dose ranged from 6.21 to $41.16 \mathrm{GBq}$ (230 to $1523 \mathrm{mCi}$ ) with a median cumulative dose of 24-96 GBq (922 mCi). RAI uptake in metastases was present in 16 patients and ranged from $0.05 \%$ to $12 \%$ (median $0.5 \%$ ). In 9 of patients the uptake of RAI was $0.5 \%$ or larger. Chemotherapy and EBRT was used in 13 and 18 patients, respectively.

The treatment of metastases was heterogeneous. Two patients had surgery because of lung metastases. In the first one a lung metastasis was excised because it was solitary and occurred after a long disease-free interval. The other patient had six surgical procedures because of small multiple metastases which were resected at other hospital because the patient preference and persistence. The same patient had also numerous surgical procedures of bone metastases. On the other hand, majority of bone metastases in our patients lesions were efficiently treated 
by EBRT. In only two patients a pathologic bone fracture necessitated surgical approach: a right hip replacement because of fracture of femur and two surgical procedures of the right ulna. Two patients had liver metastases: one of them was treated with RAI eight times and there was an uptake in liver metastases. The other patient had pulmonary and liver metastases and RAI uptake was observed in liver three times. Because of progression of liver metastases and T3-hypethyreosis she was treated also with chemotherapy (vinblastine and doxorubicin, vinblastine and cisplatin) with only partial response.

\section{Disease-free survival and disease-specific survival}

Following initial treatment, distant metastases were proven in 20 patients after follow-up of 3 to 180 months (median 44 month). Distant dissemination was diagnosed as only distant, both locoregional and distant, and after surgical treatment of locoregonal recurrence in 11, 3 , and 6 cases, respectively.

Nine patients are alive with a median follow-up of 33286 months. One patient was lost from follow-up. One patient died of causes unrelated to primary disease, while 21 patients died of thyroid carcinoma. Of the latter, 19 patients died of distant metastases, while two patients died of distant and locoregional progression of the disease. Locoregional control of the disease was achieved in 19/21 (90 \%) patients who succumbed due to HCTC.

Table 4 shows details about median length of disease-specific survival from the diagnosis of metastatic disease, 5-year disease-specific survival and 10year disease-specific survival for all patients, those with pulmonary, bone, single organ, multiple organ metastases, initially metastatic, and metastatic after disease-free interval.
Patients treated with neoadjuvant chemotherapy had a more advanced stage of disease than those who were not treated by neoadjuvant chemotherapy (Table 2 and Table 3). Estimated median disease-specific survival from the beginning of treatment in patients with and without neoadjuvant chemotherapy was 100 and 141 months (log-rank $p=0.256$ ), respectively. 5-year disease-specific survival for patients with and without neoadjuvant chemotherapy was $78 \%$ and $90 \%$, respectively. Median disease-specific survival from the diagnosis of metastatic disease in patients with and without neoadjuvant chemotherapy was 93 and 72 months, respectively (logrank $p=0.89$ ).

Median disease-specific survival from the initial treatment in patients with and without total thyroidectomy was 145 months in both groups of patients. Median disease-specific survival from the time of diagnosis of distant metastases in patients with and without total thyroidectomy was 93 months and 65 months $(p=0.32)$, respectively.

Median disease-specific survival from the initial treatment of patients with and without RAI therapy was 145 months and 100 months, respectively. Median disease-specific survival from the diagnosis of distant metastases in patients with and without RAI therapy was 93 months and 77 months, respectively. Patients treated only with surgery and RAI without EBRT and/or chemotherapy had median disease-specific survival 49 months from the initial therapy and 27 months from the diagnosis of distant dissemination.

\section{Discussion}

HCTC is a rare disease, so there are only limited data about treatment of patients with metastatic and/or locally advanced HCTC $[3,6,7,9,11,14-17,20,23,29,30]$ because

Table 4 Median estimated disease-specific survival, 5-year disease-specific survival and 10-year disease-specific survival from inital treatment and from the time of diagnosis of metastatic disease

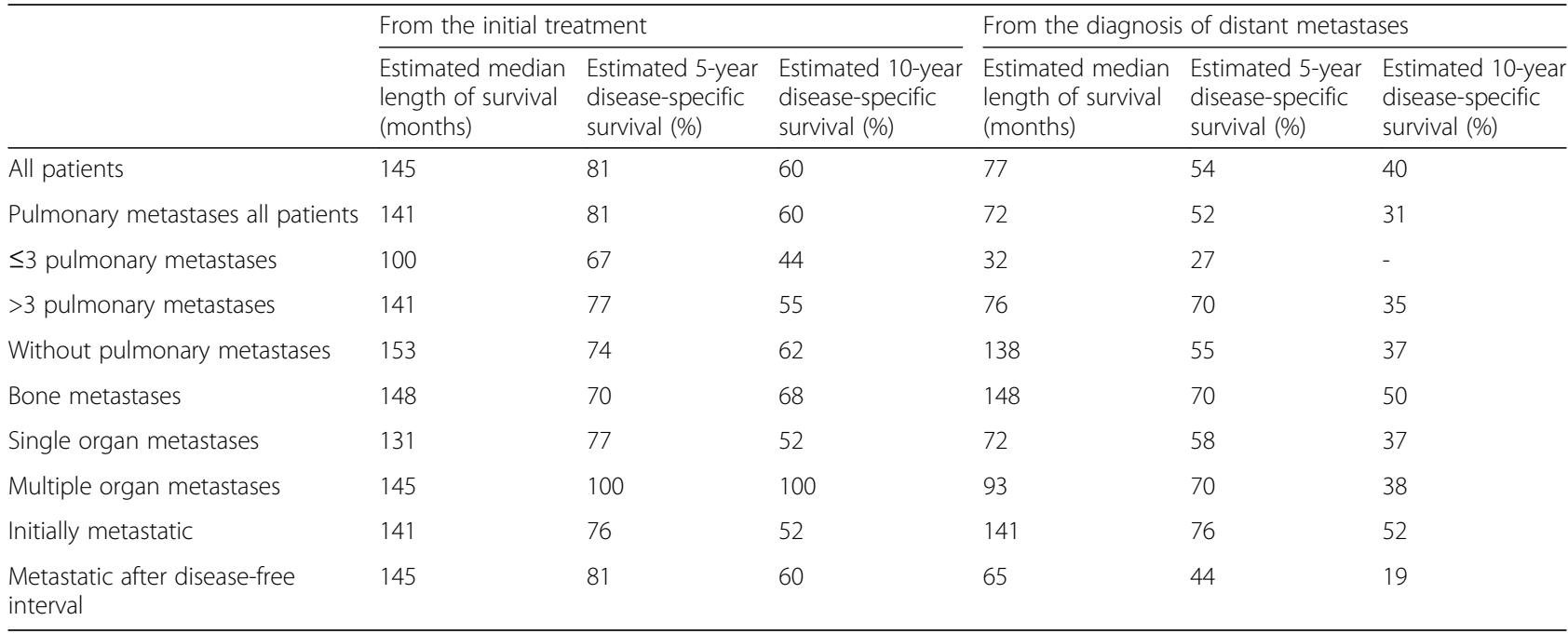


the majority of series with HCTC included only a very limited number of patients. To our knowledge this study represents the largest group of patients with distant metastases of HCTC and long follow-up in all the literature. Large primary tumors in our patients probably accounted for the high frequency of metastatic disease in our population [23]. Since the data were gathered over 39 years, many of the early cases were prior to the current epidemic of diagnosis of small and limited tumors. But a limitation of our study is that treatment was not uniform. Another limitation of our study is that only one of 13 patients with inadequate surgery underwent completion surgery, including six patients who "preferred treatment with RAI".

Total thyroidectomy and RAI ablation of thyroid remnant tissue have an impact on earlier detection of recurrence and disease-free survival and possibly also on cause-specific survival of patients with HCTC [23]. Patients with HCTC from different centers were treated with various approaches. Total or near-total thyroidectomy was conducted on patients reported by Kushchayeva et al. [1], Har-El at al. [7], Chindris et al. [22], Petric et al. [23], Khafif et al. [11], Mills et al. [20], Lopez-Penabad et al. [16], and Stojadinovic et al. [14] in $90 \%, 82 \%, 81 \%, 71 \%$, $64 \%, 52 \%, 47 \%$, and $30 \%$ of cases, respectively. Additionally, RAI ablation of thyroid remnant tissue was conducted in those reported by Chindris et al. [22], Petric et al. [23], Kushchayeva et al. [1], Mills et al. [20], Har-El at al. [7], and Khafif et al. [11] in $87 \%, 80 \%, 64 \%, 44 \%$, $18 \%$, and $9 \%$, respectively. EBRT to the neck region was conducted in $28 \%, 23 \%, 21 \%, 18 \%$, and $2 \%$ of patients reported by Lopez-Penabad et al. [16], Mills et al. [20], Petric et al. [23], Kushchayeva et al. [1], and Chindris et al. [22], respectively. The 10-year disease-specific survival was $88 \%$ [23] and only $49 \%$ in a study reported by Petric et al. [23] and Kushcayeva et al. [1], respectively. However, it should be stressed that the survival rates represent the result of both selection bias, i.e. more advanced disease in larger centers, and the effectiveness of different treatment modalities used in patients.

Our patients with metastatic HCTC had suppressed TSH with L-thyroxin. Other treatment options for metastatic HCTC are RAI, EBRT, surgery, chemotherapy, and/or targeted therapy. There is a paradigm that metastases of HCTC do not accumulate RAI. However, in 1994 Caplan et al. [9] reported normalization of elevated $\mathrm{Tg}$ concentration in two cases of HCTC after treatment with RAI [9]. Furthermore, in 2003, our group reported the uptake of RAI (range 0.1-12\%) in 11 of 16 (69\%) patients with distant metastases of HCTC from our tertiary comprehensive cancer center [15]. The updated data is presented in the current publication. RAI uptake was present in metastases in 16 of 30 patients (53\%) who had distant metastases. Uptake of RAI was $0.5 \%$ or higher in 9 of 30 patients (30\%). Similarly, LopezPenabad et al. reported that $38 \%$ of the patients with known metastases of HCTC showed RAI uptake in the period between 1944 and 1995 at the MD Anderson Cancer Center [16]. However, former data from Mayo Clinic are in disagreement with results from MD Anderson Cancer Center and our institute [22]. At Mayo, RAI scintigraphy (either TSH-stimulated or in hypothyroid state) was performed in 40 patients with metastases and RAI uptake was seen in only 9 cases $(22.5 \%)$ [22]. A possible reason for discrepant results may be the widespread use of CT and PET-CT with iodine radiocontrast media in the diagnostic work-up of patients with suspected dissemination of HCTC in the States.

RhTSH-aided RAI may be effective in RAI avid metastatic HCTC [29]. Numerous RAI-avid lesions were detected after rhTSH aided RAI therapy in five of six of our patients with HCTC [29]. Furthermore, 2 of 6 patients had partial response and one of them was long lasting [29]. Our view is therefore that RAI therapy may be effective treatment option in patients with HCTC which should not be neglected in patients with RAI avid metastases. Treatment with RAI has low toxicity and price in comparison to the treatment with tyrosine kinase inhibitors. We believe that they may be treatment of choice when metastases are non-RAI avid. But studies should be performed to assess the role of tyrosine kinase inhibitors in Hurthle cell carcinoma that is not radio-iodine avid.

Also EBRT may be an effective treatment option in metastatic HCTC. In 1986, Har-El et al. reported that after incomplete resection and EBRT of inoperable neck mass a patient survived 14 years [7]. Foote et al. from the Mayo Clinic stated that HCTC is a radiosensitive tumor [17]. Our data support their observation that postoperative EBRT prevents the recurrence of advanced resected tumors [17]. EBRT was conducted in a total of 19 patients, of whom twelve received EBRT to the neck and superior mediastinum and long-lasting locoregional control of disease was achieved in all three patients after macroscopic residual tumor resection. Furthermore, our experience confirms observation from Mayo Clinic that EBRT provide palliative relief from symptomatic metastases [17]. The effect of EBRT of bone metastases in our patients lasted from 13 to 165 months (median 93 months).

Surgical procedure is another useful treatment option for distant metastasis in selected cases. In our patients, surgical therapy of metastatic disease and/or local recurrence included functional neck dissection, resection of lung, bone, brain and liver metastasis, nephrectomy, laminectomy, hip replacement, superficial parotidectomy, tracheal shaving, and tracheostomy. Khafif et al. reported that one patient who had a resection of a lung 
metastasis was alive and free of disease 18 years after his initial surgery [11].

Our previously published data showed that chemotherapy may be effective in primary HCTC [30]. Chemotherapy in neoadjuvant setting decreased size of primary HCTC in $43 \%$ of cases [30]. Lopez-Penabad et al. reported that systemic chemotherapy was administered to $27 \%$ of patients, mainly those with unresectable or progressive metastatic disease [16]. Thirteen percent of patients received chemotherapy initially as a radiosensitizing agent, and the remaining $87 \%$ of patients received a full course of treatment [16]. The agents that were used most commonly were doxorubicin alone in $43 \%$ of patients, doxorubicin plus cisplatin in $38 \%$ of patients, cisplatin alone in $10 \%$ of patients, and an unspecified agent in the reviewed records of $9 \%$ of patients [16].

There is a bias about performing a total thyroidectomy and duration of survival in our group of patients. Larger proportion of patients without a total or completion thyroidectomy had more advanced disease, so they were treated with EBRT, chemotherapy and radioiodine more frequently than patients after a total thyroidectomy. Interestingly, estimated median disease-specific survival from the initial treatment in patients with and without total thyroidectomy was 145 months in both groups of patients. Furthermore, there was no statistically significant difference in median disease-specific survival of both groups of patients from the time of diagnosis of distant metastases. This suggests possible impact of more aggressive combined treatment on survival of patients.

Pittas et al. reported that nine patients with bone metastases of HCTC have longer survival in comparison to 74 patients with bone metastases of follicular, papillary, or undifferentiated thyroid carcinoma [31]. Our results confirm their observation that patients with metastatic HCTC have a long survival. Median disease-specific survival from the diagnosis of metastatic disease for our 8 patients with bone metastases was 148 months. Five-year and ten-year disease-specific survival was $70 \%$ and $50 \%$, respectively. It is interesting that our four patients with multiple organ metastases had $100 \% 5$-year survival from the first treatment and $75 \%$ from the time of diagnosis of distant dissemination. It should be stressed that, the number of patients with multiple organ metastases in our series is very small. Survival of larger series of patients with multiple metastases should be analyzed in order to find out if these patients have more favorable prognosis in comparison to solitary organ metastases. Most likely these four patients had more slowly progressing tumor in comparison to other 28 patients. The other possible explanation is that their tumor was very responsive to treatment: all four had RAI ablation of thyroid remnant, three had therapy with chemotherapy and RAI and all four had EBRT.
Longer survival of patients with HCTC in comparison to other types of differentiated thyroid carcinoma is probably due to more indolent course of HCTC [31]. However, also HCTC is a progressive disease, so treatment of recurrent and/or metastatic HCTC is necessary in all those patients who are not extremely old or with severe concomitant diseases.

\section{Conclusions}

Ten-year disease-specific survival for patients with metastatic HCTC was $60 \%$. Patients with bone metastases live longer than patients with lung metastases.

\section{Consent}

Written informed consent was obtained from the patient for the publication of this report and any accompanying images.

\section{Availability of data and materials}

There are no additional data or materials to be shared.

\begin{abstract}
Abbreviations
B: bone ChT, chemotherapy; DDLTP: dead of distant and locoregional tumor progression; DDM: dead of distant metastases; DOC: dead of other causes; EBRT: external beam radiotherapy; FTC: follicular thyroid cancer; GBq: gigabecquerel; HCTC: Hürthle cell thyroid carcinoma; LFU: lost to follow-up; mCi: millicurie; L: lungs; LO: lobectomy; MIBI: methoxyisobutylisonitrile; PET-CT: positron emission tomography and computerized tomography; PT: partial thyroidectomy;

RAl: radioiodine; rhTSH: recombinant human thyrotropin; RND: modified radical neck dissection; R1: microscopic residual tumor; R2: macroscopic residual tumor; Tg: thyroglobulin; TNM: tumor, lymph nodes, distant metastases; TSH: thyrotropin; T: total or near total thyroidectomy; UICC: Union for International Cancer Control; US: ultrasound.
\end{abstract}

Competing interests

The authors declare that they have no competing interests.

\section{Authors' contributions}

NB participated in the design of the study, partially collected data and performed the statistical analysis and drafted manuscript. ASP, BVK and TC collected data. BG reviewed slides. MMM participated in design of the study, prepared tables and drafted the manuscript. All authors read and approved the final manuscript

\section{Acknowledgements}

The paper was supported by a research program, P3-0289, by the Ministry of Higher Education, Science and Sport of Slovenia.

\section{Author details}

${ }^{1}$ Department of Surgical Oncology, Institute of Oncology, Zaloska 2, SI-1000 Ljubljana, Slovenia. ${ }^{2}$ Department of Nuclear Medicine, Institute of Oncology, Zaloska 2, SI-1000 Ljubljana, Slovenia. ${ }^{3}$ Department of Pathology, Institute of Oncology, Zaloska 2, SI-1000 Ljubljana, Slovenia. ${ }^{4}$ Department of Radiology, Institute of Oncology, Zaloska 2, SI-1000 Ljubljana, Slovenia.

Received: 15 August 2015 Accepted: 15 February 2016

Published online: 26 February 2016

\section{References}

1. Kushchayeva Y, Duh Q-Y, Kebebew E, Clark OH. Prognostic indications for Hürthle cell cancer. World J Surg. 2004;28:1266-70.

2. Bhattacharyya N. Survival and prognosis in Hürthle cell carcinoma of the thyroid gland. Arch Otolaryngol Head Neck Surg. 2003;129:207-10. 
3. Hedinger C, Williams ED, Sobin LH. The WHO histological classification of thyroid tumors: a commentary on the second edition. Cancer. 1989;63:908-11.

4. Ganly I, Ricarte Filho J, Eng S, Ghossein R, Morris LG, Liang Y, Socci N, Kannan K, Mo Q, Fagin JA, Chan TA. Genomic dissection of Hurthle cell carcinoma reveals a unique class of thyroid malignancy. J Clin Endocrinol Metab. 2013;98:E962-72.

5. Thompson NW, Dunn EL, Batsakis JG, Nishiyama RH. Hurthle cell lesions of the thyroid gland. Surg Gynecol Obstet. 1974;139:555-60.

6. Watson RG, Brennan MD, Goellner JR, van Heerden JA, McConahey WM, Taylor WF. Invasive Hurthle cell carcinoma of the thyroid: natural history and management. Mayo Clin Proc. 1984;59:851-5.

7. Har-El G, Hadar T, Segal K, Levy R, Sidi J. Hurthle cell carcinoma of the thyroid gland: a tumor of moderate malignancy. Cancer. 1986;57:1613-7.

8. Carcangiu ML, Bianchi S, Savino D, Voynick IM, Rosai J. Follicular Hürthle cell tumors of the thyroid gland. Cancer. 1991;68:1944-53.

9. Caplan RH, Abellera RM, Kisken WA. Hurthle cell neoplasms of the thyroid gland: reassessment of functional capacity. Thyroid. 1994;4:243-8.

10. McDonald MP, Sanders LE, Silverman ML, Chan HS, Buyske J. Hürthle cell carcinoma of the thyroid gland: prognostic factors and results of surgical treatment. Surgery. 1996;120:1000-5.

11. Khafif A, Khafif RA, Attie JN. Hurthle cell carcinoma: a malignancy of lowgrade potential. Head Neck. 1991;21:506-11.

12. Stojadinovic A, Ghossein RA, Hoos A, Urist MJ, Spiro RH, Shah JP, Brennan MF, Shaha AR, Singh B. Hürthle cell carcinoma: a critical histopathological appraisal. J Clin Oncol. 2001;19:2616-25.

13. Sugino K, Ito K, Mimura T, Kameyama K, Iwasaki H, Ito K. Hürthle cell tumor of thyroid: analysis of 188 cases. World J Surg. 2001;25:1160-3.

14. Stojadinovic A, Hoos A, Ghossein RA, Urist MJ, Leung DH, Spiro RH, Shah JP, Brennan MF, Singh B, Shaha AR. Hürthle cell carcinoma: a 60-year experience. Ann Surg Oncol. 2002;9:197-203.

15. Besic N, Vidergar-Kralj B, Frkovic-Grazio S, Movrin-Stanovnik T, Auersperg M. The role of radioactive iodine in the treatment of Hurthle cell carcinoma of the thyroid. Thyroid. 2003;13:577-84.

16. Lopez-Penabad L, Chiu AC, Hoff AO, Schultz P, Gaztambide S, Ordoñez NG, Sherman SI. Prognostic factors in patients with Hürthle cell neoplasms of the thyroid. Cancer. 2003;97:1186-94.

17. Foote RL, Brown PD, Garces YI, Mclver B, Kasperbauer JL. Is there a role for radiation therapy in the management of Hurthle cell carcinoma? Int J Radiat Oncol Biol Phys. 2003;56:1067-72

18. Paunovic I, Krgovic K, Tatic S, Diklic A, Zivaljevic V, Kalezic N, Havelka M. Surgery for thyroid Hürthle cell tumours - a single institution experience. Eur J Surg Oncol. 2006;32:458-61.

19. Ghossein RA, Hiltzik DH, Carlson DL, Patel S, Shaha A, Shah JP, Tuttle RM, Singh B. Prognostic factors of recurrence in encapsulated Hurthle cell carcinoma of the thyroid gland: a clinicopathologic study of 50 cases. Cancer. 2006;106:1669-76.

20. Mills SC, Haq M, Smellie WJ, Harmer C. Hurthle cell carcinoma of the thyroid: retrospective review of 62 patients treated at the Royal Marsden Hospital between 1946 and 2003. Eur J Surg Oncol. 2009;35:230-4.

21. Bishop JA, Wu G, Tufano RP, Westra WH. Histological patterns of locoregional recurrence in Hürthle cell carcinoma of the thyroid gland. Thyroid. 2012;22:690-4.

22. Chindris AM, Casler JD, Bernet VJ, Rivera M, Thomas C, Kachergus JM, Necela BM, Hay ID, Westphal SA, Grant CS, Thompson GB, Schlinkert RT, Thompson EA, Smallridge RC. Clinical and molecular features of hürthle cell carcinoma of the thyroid. J Clin Endocrinol Metab. 2015;100:55-62.

23. Petric R, Gazic B, Besic N. Prognostic factors for disease-specific survival in 108 patients with Hürthle cell thyroid carcinoma: a single-institution experience. BMC Cancer. 2014:14:777.

24. Nagar S, Aschebrook-Kilfoy B, Kaplan EL, Angelos P, Grogan RH. Hurthle cell carcinoma: an update on survival over the last 35 years. Surgery. 2013:154: 1263-71.

25. Rosai J. Tumors of thyroid gland. In: Rosai J, Carcangiu ML, DeLellis RA editors. Atlas of tumor pathology. Washington: Armed Forces Institute of Pathology; 1992. p. 31-50.

26. LiVolsi VA, Baloch ZW. Follicular neoplasms of the thyroid: view, biases, and experiences. Adv Anat Pathol. 2004;11:279-87.

27. Besic N, Hocevar M, Zgajnar J, Petric R, Pilko G. Aggressiveness of therapy and prognosis of patients with Hürthle cell papillary thyroid carcinoma. Thyroid. 2006;16:67-72.
28. Sobin LH, Gospodarowicz MK, Wittekind C. Thyroid gland (ICD-O C73). In: Sobin LH, Gospodarowicz MK, Witekind C, editors. TNM Classification of Malignant Tumours. 7th ed. New York: Wiley Blackwell; 2009. p. 58-62.

29. Zagar I, Schwarzbartl-Pevec A, Vidergar-Kralj B, Horvat R, Besic N. Recombinant human thyrotropin-aided radioiodine therapy in patients with metastatic differentiated thyroid carcinoma. J Thyroid Res. 2012, 670180.

30. Besic N, Auersperg M, Gazic B, Dremelj M, Zagar I. Neoadjuvant chemotherapy in 29 patients with locally advanced follicular or Hurthle cell thyroid carcinoma: a phase 2 study. Thyroid. 2012;22:131-7.

31. Pittas AG, Adler M, Fazzari M, Tickoo S, Rosai J, Larson SM, Robbins RJ. Bone metastases from thyroid carcinoma: clinical characteristics and prognostic variables in one hundred forty-six patients. Thyroid. 2000;10:261-8.

\section{Submit your next manuscript to BioMed Central and we will help you at every step:}

- We accept pre-submission inquiries

- Our selector tool helps you to find the most relevant journal

- We provide round the clock customer support

- Convenient online submission

- Thorough peer review

- Inclusion in PubMed and all major indexing services

- Maximum visibility for your research

Submit your manuscript at www.biomedcentral.com/submit
) Biomed Central 